\title{
Tuberculosis Treatment Completion for Tribal Patients in Kerala: Needs Constant Push!
}

\author{
Jyothilakshmi Chettipparan Rajan ${ }^{*}$, Tanu Anand ${ }^{2}$, Sharath Burugina Nagaraja ${ }^{3}$, \\ Sabu Kochupurackal Ulahannan ${ }^{4}$, Karuna Sagili ${ }^{5}$, Manu Muraleedharan Sarojini' ${ }^{6}$
}

\author{
${ }^{1}$ Wayanad Social Service Society, Wayanad, Kerala, India \\ ${ }^{3}$ Department of Community Medicine, ESIC Medical College, and PGIMSR, Bengaluru, India \\ ${ }^{4}$ Institute of Public Health, Bengaluru, India \\ ${ }^{5}$ Department of TB and communicable diseases, The Union, New Delhi, India \\ ${ }^{6}$ State TB Demonstration and Training Centre, Trivandrum, India \\ Email: *crjyothilakshmi@gmail.com
}

${ }^{2}$ Department of Community Medicine, North Delhi Municipal Corporation Medical College, Hindu Rao Hospital, Delhi, India

How to cite this paper: Rajan, J.C., Anand, T., Nagaraja, S.B., Ulahannan, S.K., Sagili, K. and Sarojini, M.M. (2019) Tuberculosis Treatment Completion for Tribal Patients in Kerala: Needs Constant Push! Journal of Tuberculosis Research, 7, 185-201. https://doi.org/10.4236/jtr.2019.74018

Received: May 29, 2019

Accepted: October 26, 2019

Published: October 29, 2019

Copyright $\odot 2019$ by author(s) and Scientific Research Publishing Inc. This work is licensed under the Creative Commons Attribution International License (CC BY 4.0).

http://creativecommons.org/licenses/by/4.0/

cc) (i) Open Access

\begin{abstract}
Introduction: Tuberculosis (TB) incidence among tribal patients is high owing to their social and geographic vulnerability. Ensuring adherence to TB treatment among them remains a challenging task as it is dependent on socio-cultural and environmental factors. Objective: 1) To know the individuals' perception of TB disease and anti-TB treatment; 2) To explore the personal, social, family and cultural factors influencing on patient's treatment adherence; 3) To identify the challenges faced by health care providers in delivering services to the tribal population. Material and Methods: A descriptive qualitative study conducted among tribal patients $(\mathrm{n}=16)$ and health providers $(n=6)$ of Manathavady TB unit, Wayanad District of Kerala. The data were collected through in-depth interviews (IDIs), audio-recorded in Malayalam, transcribed verbatim and translated into English. Transcripts were analysed using manual descriptive content analysis. Results: Most of the patients were oriented about the importance of completing TB treatment though lacked awareness about its causation. The supportive attitude of the community further encouraged them to continue TB treatment. However, substance abuse emerged as the biggest challenge to treatment adherence particularly among males. While accessibility to the health system, animal confrontation, and disaster risk emerged as barriers owing to the geographic landscape of the community, health services were found to be acceptable, available and affordable to all the patients. No stigma or discrimination was perceived by the patients at family, community and health system level. However, their beliefs in herbal medicines and conduct of certain rituals delayed them for seeking care. The personal commitment of the health care staff
\end{abstract}


helped the TB patients to adhere better with the treatment thereby yielding best results. Conclusion: The TB treatment adherence among the tribal population was satisfactory due to personal, social and health system support. However, alcoholism and geographic vulnerability were perceived as the challenges in ensuring treatment adherence.

\section{Keywords}

Treatment Adherence, Kerala, Qualitative, Operational Research

\section{Introduction}

In India, tuberculosis (TB) remains as major public health and accounts to nearly $27 \%$ of the global burden [1]. Despite, the implementation and efforts from the Revised National TB Control Program (RNTCP) since 1997 onwards the incidence of $\mathrm{TB}$ has been at an estimated 211 cases per lakh population [1]. The distribution of TB is uneven across different sections of the population in the country. The unreached, marginalised communities, people facing socio-economic challenges, those working and living in high-risk settings and poorest are accounted for a huge load of TB [2].

The studies conducted among the tribal population or communities in various parts of the country suggest that this population has a higher TB incidence when compared to the general population [3]. It is seen that poverty, undernutrition, illiteracy, alcoholism, substance abuse and poor access to health care are few of the factors responsible for this [4]. The tribal population is underprivileged group with complex social structure and their adherence to the long duration of tuberculosis treatment is also dependent on many socio-cultural-environmental factors. This apart, the interaction between patients and health care providers and other social influences are important dimensions for understanding adherence [4] [5]. Though TB patients receive treatment from treatment supporters, lack of awareness and social stigma are barriers in the successful implementation of RNTCP and ensuring treatment adherence [6].

The state of Kerala in deep south India has a good general health system and has achieved most of the national targets set by the Government of India for most of the health programmes including the RNTCP [7]. The state has also undertaken vulnerability mapping as a part of TB elimination plan which shows that there are equity issues in delivering services to the tribal communities [8]. The highest concentration of scheduled tribes is seen in Wayanad district (37.36\%) of Kerala where TB remains a major health issue [9].

The treatment adherence mechanisms under RNTCP have a spectrum of activities for patients and health care providers which include training programs, health education, a routine reminder for patients to consume drugs and follow-up examination, financial incentives and reimbursements to patients direct or indirect costs, peer assistance, directly observed treatment and loss to retrieval 
actions. But still, the treatment adherence continues to be a challenge in tribal areas due to the geographic and social milieu of tribal population [10] [11]. Though many studies have been conducted globally on adherence among TB patients there is sparse literature from Kerala, India to understand the multifaceted dimensions and determinants of treatment adherence among the tribal population in a state which has remarkably performed well in health and development indicators over the years. This understanding helps the policy makers and the programme implements to devise newer strategies with an emphasis on weakening links. We conducted this study 1) to know the individual's perception of TB disease and anti-TB treatment; 2) to explore the personal, social, family and cultural factors influencing on patient's treatment adherence; 3) to identify the challenges faced by health care providers in delivering services to the tribal population.

\section{Methods}

\subsection{Study Design}

A qualitative study involving key informants' interviews of TB patients and health care providers.

\subsection{General Setting}

The district of Wayanad has a population of 0.82 million with a literacy rate of $89 \%$ and with a population density of 384 persons per square kilometre [12]. It is situated in the top north-east corner of Kerala and is known for its cool temperature and woodlands. A various group of tribal population is living in different ecological conditions in Mananthavady block (sub-district administrative unit). Paniya, Adiya, and Kattunaikkans group are the most marginalized tribal communities in this block especially on parameters of social, economic and education.

\subsection{Specific Setting}

The study was conducted in Mananthavady TB unit, Wayanad district. The RNTCP is being implemented in the district since 2001. The district hospital is the only tertiary public health facility to deliver health care services to tribal communities and other less privileged sections of Wayanad.

\subsection{Study Population}

All the TB cases registered in Mananthavady tuberculosis unit (an RNTCP program management unit for 0.5 million population) during January through June 2018. During this period, there were 663 tuberculosis cases registered under the program. Of which 118 cases were notified from the private sector and 545 cases were from the public sector. Nearly 24\% (162) of patients registered belonged to the tribal population. The key personnel involved in the implementation of the programme in the region were also interviewed. 


\subsection{Sample Size and Sampling}

There were 56 cases registered for treatment during the study period. We selected the patients randomly and conducted the interviews until the saturation point was obtained. The six key informants from the said TB unit who were proficient and willing to participate were chosen. The cadre of the key informants interviewed included the medical officer, senior treatment supervisor (STS), Coordinator, Accredited Social Health Activist (ASHA) workers and Anganwadi teacher.

For the purpose of the study we proposed the following operational definitions 1) Adherence: The degree to which the person's behaviour corresponds with the agreed recommendations from a health care provider; 2) Non-adherence: The degree to which the person's behaviour does not correspond with the agreed recommendations from a health care provider.

\subsection{Data Variables, Sources of Data and Data Collection}

Qualitative data were collected through key informant interviews (KIIs) of patients and health care providers. Interviewers guide were developed after discussion with the key persons involved in TB care to collect information. A pilot study was conducted to review the interview guide and prompts Interview guides were semi-structured, open-ended with probing questions. The questions mainly included the following areas 1) personal factors like level of awareness and knowledge, motivation, employment status, treatment duration, substance abuse and adherence of the patient to the treatment; 2) social factors of adherence which included accessibility, availability, affordability and acceptability; 3 ) Family factors like emotional and material support; 4) Community factors which include attitude and support of colony people; 5) Cultural factors that include health-seeking behaviour, belief system, and stigma and discrimination because of caste and illness were identified.

16 patients registered during January 2018 to June 2918 were randomly selected from TB register. Interviews were carried out by principal investigator in local vernacular language (Malayalam). The principal investigator is a female social worker and community health worker with training in qualitative research methods. The participants were made aware by explaining them about the study and the need for their involvement in it. Informed written consent was obtained before the interview. After participants approval, the interviews were audio recorded and conducted at a time and place convenient to them and they lasted for 30 to 45 minutes. All the patients were interviewed till the point of saturation is obtained. The study was conducted at the houses of patients as per their convenient time and date. Family members of patients were presented at the time of interview in most of the cases depends upon the size of home. Interviews of 15 patients were done at the houses of patient. Only one interview conducted in anganwadi to ensure privacy of that patient. Interviews with health care providers done in TB unit except ashas. Ashas were interviewed in their respective homes. 


\subsection{Data Analysis}

The data were collected by interview using the interview guide and all the conversations were audio recorded. Recorded data were transcribed and translated into English. Transcripts were made the same day based on the verbatim notes of in-depth interviews by the PI (JL). The transcripts obtained were compiled and the PI read the transcripts to become familiar with the data. Manual descriptive content analysis was used by the PI for analysing the transcripts. It was reviewed by the second investigator (TA) to reduce interpretation bias and increase to the credibility of the findings. The decision on coding rules and theme generation was taken by using standard procedures and consensus. Any distinction between the two the investigators were resolved by discussion. A total of 26 codes were created and 8 themes were derived from them. The outcomes have been exhibited in eight sections. The main themes derived were personal, social, familial, community, health system, cultural factors and the perceived enablers and barriers by health care providers. The themes that have emerged under every one of the sub-headings are presented.

\subsection{Ethics Approval}

The ethics approval was obtained from the Union EAG, Paris and administrative approvals were received from State Tribal Welfare Department of Kerala and the Department of Health and Family Welfare, State Health Services, Kerala. The permission was also obtained from the District TB officer of Wayanad district. The study followed the principles of confidentiality, the voluntariness of participation and informed consent. The study objectives, methods, and guiding principles were presented to the patient's family giving them the chance to ensure that the investigation was done to the greatest advantage of the family. Along these lines, all participants in the study were educated about the purpose and significance of the study. Confidentiality and privacy of the study participants were ensured to the best possible extent.

\section{Results}

\subsection{Characteristics of Study Subjects}

Most TB patients 33 (59\%) were in the age group of 25 - 69 years, 30 (54\%) were males, 44 (79\%) were married and 46 (82\%) were working. Most of them worked in unorganised sectors as labourers however during the study period only four of them were working. Majority of the patients were from Paniya, Adiya, Bettakuruma and Kattunaika community. Nearly 20 (30\%) of the population consumed alcohol and $40(70 \%)$ had the habit of using tobacco. The socio-demographic characteristics of the study population are shown in Table 1.

\subsection{Patients Perception and Factors Influencing Adherence}

We achieved the saturation point on conducting the interviews of sixteen patients (10 males and 6 females). The perception of the disease, the anti-TB 
treatment and the factors influencing patient's adherence categorized into the following themes (3.2.1) Personal (3.2.2) Social (3.2.3) Familial (3.2.4) Community (3.2.5) Health system and (3.2.6) Cultural factors.

Table 1. Socio-demographic characteristics of study population.

\begin{tabular}{|c|c|c|}
\hline \multicolumn{2}{|c|}{ Characteristics } & Number (\%) \\
\hline \multirow{4}{*}{ Age (years) } & $0-14$ & $6(10.7)$ \\
\hline & $15-24$ & $12(21)$ \\
\hline & $25-64$ & $33(59)$ \\
\hline & $\geq 65$ & $5(9)$ \\
\hline \multirow{2}{*}{ Gender } & Male & $30(54)$ \\
\hline & Female & $26(46)$ \\
\hline \multirow{2}{*}{ Marital Status } & Married & $44(79)$ \\
\hline & Unmarried & $12(21)$ \\
\hline \multirow{3}{*}{ Occupation } & Working & $46(82)$ \\
\hline & Not working & $7(12)$ \\
\hline & Studying & $3(6)$ \\
\hline \multirow{3}{*}{ Type of Tuberculosis } & Pulmonary & $42(75)$ \\
\hline & Extrapulmonary & $13(23)$ \\
\hline & both & $1(2)$ \\
\hline \multirow{3}{*}{ Type of Patient } & New case & $44(79)$ \\
\hline & Transferred-in & $1(2)$ \\
\hline & Recurrent case & $11(19)$ \\
\hline \multirow{2}{*}{ Case definition } & Microbiologically confirmed & $37(66)$ \\
\hline & clinically diagnosed & $19(34)$ \\
\hline \multirow{4}{*}{ Use of Tobacco } & No usage & $16(29)$ \\
\hline & Use of Smoke form & $2(4)$ \\
\hline & Use of Smokeless form & $34(61)$ \\
\hline & Uses both forms & $4(6)$ \\
\hline \multirow{3}{*}{ History of Alcohol intake } & Yes & $20(36)$ \\
\hline & No & $32(57)$ \\
\hline & Not recorded & $4(7)$ \\
\hline \multirow{2}{*}{ HIV Status } & Reactive & $2(4)$ \\
\hline & Non-reactive & $54(96)$ \\
\hline \multirow{3}{*}{ Diabetes status } & Diabetic & $4(7)$ \\
\hline & Non-diabetic & $47(84)$ \\
\hline & not recorded & $5(9)$ \\
\hline \multirow{2}{*}{ Health facility diagnosed } & Public & $56(100)$ \\
\hline & Private & $0(0)$ \\
\hline \multirow{2}{*}{ Treatment outcome } & Favourable & $45(80)$ \\
\hline & Unfavourable & $11(20)$ \\
\hline
\end{tabular}




\subsubsection{Personal Factors}

Level of Awareness and adherence: Almost all the participant were unaware of causation and symptoms of TB that resulted in a delay in diagnosis and treatment initiation. All the participants except two had knowledge about the importance of complete treatment. Only two patients were ignorant because of the language barrier and personal situations unique to those two participants (Table 2).

"In our community, most of them consult a doctor in the last stage; that is the specialty ... whatever may be the symptoms, even if it is fever or some other illness, our community people will delay taking treatment and visit the hospital in the last stage" (46-year-old female patient)

"I was very much afraid of injection, so once I got TB, I refused to go to the hospital and also ran away to the forest on seeing Asha worker." (24-year-old male patient)

Table 2. Patients perception and factors (Personal, Social, Familial \& Community) influencing adherence.

\begin{tabular}{|c|c|c|c|}
\hline $\begin{array}{l}\text { Factors influencing } \\
\text { treatment adherence }\end{array}$ & $\begin{array}{l}\text { Number of } \\
\text { participants }\end{array}$ & Participants characteristics & Results \\
\hline $\begin{array}{l}\text { Personal } \\
\text { a) Level of awareness } \\
\text { \& Knowledge }\end{array}$ & $\begin{array}{l}16 \\
14 \\
2\end{array}$ & $\begin{array}{l}\text { Not aware of causation and } \\
\text { symptoms } \\
\text { Knowledge about the } \\
\text { importance of completion of } \\
\text { treatment } \\
\text { Ignorant about the importance } \\
\text { of treatment completion }\end{array}$ & $\begin{array}{l}\text { Delayed diagnosis and } \\
\text { treatment initiation } \\
\text { Better adherence } \\
\text { Unfavourable treatment } \\
\text { outcome }\end{array}$ \\
\hline $\begin{array}{l}\text { b) Motivation to } \\
\text { continue treatment }\end{array}$ & $\begin{array}{l}11 \\
4 \\
1\end{array}$ & $\begin{array}{l}\text { Constant encouragement from } \\
\text { health staff and family } \\
\text { members } \\
\text { Less self-motivation } \\
\text { Fear and anxiety }\end{array}$ & $\begin{array}{l}\text { Favourable treatment } \\
\text { outcome } \\
\text { Unfavourable treatment } \\
\text { outcome } \\
\text { Skipped doses }\end{array}$ \\
\hline $\begin{array}{l}\text { c) Employment status } \\
\text { and treatment duration }\end{array}$ & 16 & Stopped working & $\begin{array}{l}\text { Better adherence but } \\
\text { financial constraints }\end{array}$ \\
\hline d) Substance abuse & 16 & $\begin{array}{l}\text { Male and female patients were } \\
\text { using alcohol, tobacco and } \\
\text { chewing beetle nut }\end{array}$ & $\begin{array}{l}\text { Favourable treatment } \\
\text { outcome through constant } \\
\text { motivation by health staff }\end{array}$ \\
\hline $\begin{array}{l}\text { Social } \\
\text { a) Accessibility }\end{array}$ & 11 & $\begin{array}{l}\text { Difficulty to reach hospital } \\
\text { because of long distance and } \\
\text { animal confrontation }\end{array}$ & $\begin{array}{l}\text { Managed well with the } \\
\text { support of family and } \\
\text { health care staff }\end{array}$ \\
\hline b) Acceptability & 16 & $\begin{array}{l}\text { All the patient received best } \\
\text { care }\end{array}$ & Better adherence \\
\hline c) Availability & $\begin{array}{l}14 \\
2\end{array}$ & $\begin{array}{l}\text { Health care staff were available } \\
\text { Physician was not available, but } \\
\text { drugs were available }\end{array}$ & $\begin{array}{l}\text { Better adherence } \\
\text { Better adherence }\end{array}$ \\
\hline Familial & 14 & $\begin{array}{l}\text { Family members provided } \\
\text { emotional and material support }\end{array}$ & Better treatment adherence \\
\hline Community & $\begin{array}{l}2 \\
2\end{array}$ & $\begin{array}{l}\text { No community support only } \\
\text { family support } \\
\text { Both family and community } \\
\text { didn't support }\end{array}$ & $\begin{array}{l}\text { Better treatment outcome } \\
\text { Unfavourable treatment } \\
\text { outcome }\end{array}$ \\
\hline
\end{tabular}


Motivation to continue treatment. Constant encouragement from family members, health care staff especially DOT provider, Asha worker and Anganwadi teacher motivated all patients (except four) for treatment adherence. Fear and anxiety about the treatment resulted in one of the participant's decision to skip doses (Table 2).

Employment status and treatment duration: All of them stopped working due to physical illness. Consequentially, they had financial constraints, but it helped towards better adherence. Though, long duration of treatment was a barrier to patients' economic sustainability (Table 2).

Substance abuse: Male patients consumed alcohol, chewed tobacco and smoked beedis. Health workers found it difficult to administer medicines to them and making them adhere to treatment. All female participants except one were chewing beetle nut and tobacco but it didn't affect their treatment adherence (Table 2).

\subsubsection{Social Factors}

> Accessibility to care services: Overall eleven patients encountered difficulties to reach hospital especially during emergencies. The confrontation of animals especially in unusual times was the major threat to patients and health care providers. Though link roads were constructed to all tribal areas, patients had to walk long distances to catch bus and bus services were not available all the time. Except for two patients all adhered to treatment because of self-motivation, constant family and community support and contribution of health care staff. Patients reported having received their drugs and food kits even during the floods (Table 2).

"No, it was not much of an issue as I was able to walk so, I had had only to catch the bus on time and go to the hospital. But yes, if one becomes seriously ill or too weak to walk, then it is rather difficult to travel by bus, then one must depend on a private vehicle. They are not readily available here. Then travel expenses become higher". (37-year-old male patient)

Acceptability: All the patients were received with the utmost care and the health care providers had positive enforcement on information and treatment (Table 2).

> Availability. Fourteen participants said that health care providers were always available in the hospital. Only two participants didn't meet the physician when they reached the hospital. No shortage of drugs was reported even during exigencies (Table 2).

\subsubsection{Familial Factors}

Patients' families acted as the primary support system and provided emotional and material support with no reported indifference or isolation. In almost all the cases, family members accompanied the participants to the hospital (Table 2).

\subsubsection{Community Factors}

Majority of the participants said that the community people were supportive. 
Only two participants said that only their family supported and not the colony people. Two other participants said that their community did not support (Table 2).

Participant's comment about family and community support is as follows:

" $M y$ elder sister took care of me always. I never feel isolated or lonely because of TB. I myself kept a distance from them since it is an infectious disease. I don't want to give my illness to others. Colony members are also very supportive. I used to attend marriage and other social functions of my community. Even today, I attended one marriage" (47-year-old male patient)

\subsubsection{Health System Factors}

Attitude: All health staff treated them with empathetic understanding and gave them personal attention according to the uniqueness of each patient (Table 3).

Utilisation of services. All patients received all services offered under RNTCP including free food kits (Table 4).

Table 3. Patients perception and factors (Health system and Cultural factors) influencing adherence.

\begin{tabular}{|c|c|c|c|}
\hline $\begin{array}{l}\text { Health System } \\
\text { a) Attitude }\end{array}$ & 16 & $\begin{array}{l}\text { All health staff treated with } \\
\text { empathetic understanding and gave } \\
\text { personal attention }\end{array}$ & $\begin{array}{l}\text { Favourable treatment } \\
\text { outcome }\end{array}$ \\
\hline $\begin{array}{l}\text { b) Utilisation of } \\
\text { services }\end{array}$ & 16 & Received all services offered by RNTCP & $\begin{array}{l}\text { Favourable treatment } \\
\text { outcome }\end{array}$ \\
\hline $\begin{array}{l}\text { Cultural } \\
\text { a)Health seeking } \\
\text { behaviour }\end{array}$ & $\begin{array}{l}15 \\
1\end{array}$ & $\begin{array}{l}\text { Took allopathic treatment } \\
\text { Initially visited faith healer later stage } \\
\text { took allopathic treatment }\end{array}$ & $\begin{array}{l}\text { Favourable treatment } \\
\text { outcome } \\
\text { Favourable treatment } \\
\text { outcome }\end{array}$ \\
\hline b) AYUSH & 2 & Initially inclined to ayurvedic treatment & $\begin{array}{l}\text { Later stage took allopathy } \\
\text { medicines }\end{array}$ \\
\hline $\begin{array}{l}\text { c) Belief system and } \\
\text { rituals }\end{array}$ & 16 & $\begin{array}{l}\text { Early days all patients performed } \\
\text { poojas, tied sacred knots and relied } \\
\text { upon traditional plant-based medicines }\end{array}$ & $\begin{array}{l}\text { Approached RNTCP in } \\
\text { the later stage and cured }\end{array}$ \\
\hline $\begin{array}{l}\text { d) Stigma and } \\
\text { discrimination }\end{array}$ & 15 & $\begin{array}{l}\text { Only one patient felt stigma and } \\
\text { indifference from their own community } \\
\text { people }\end{array}$ & $\begin{array}{l}\text { Everyone completed } \\
\text { treatment }\end{array}$ \\
\hline e) Language barrier & 16 & Never felt communication problem & $\begin{array}{l}\text { Better treatment } \\
\text { adherence }\end{array}$ \\
\hline
\end{tabular}

Table 4. Perception of health care providers about enablers and barriers of treatment adherence.

\begin{tabular}{ccc}
\hline SLNO & $\begin{array}{c}\text { Enablers for smooth } \\
\text { implementation of RNTCP services }\end{array}$ & Barriers encountered \\
\hline 1 & Provider from tribal community & Intense belief in spirituality \\
2 & Positive Perception of health staff & Substance abuse \\
3 & Good Intersectoral collaboration & Animal confrontation \\
4 & Training especially for field staff & Disaster prone areas \\
\hline
\end{tabular}


Participant's response to the attitude of health staff is as follows:

"Everybody showed sincerity towards me. When a health inspector visited our panchayat, he used to visit our house also. He always communicated everything with us over the phone. He scheduled plans for the next day and communicated them to ASHA worker one day in advance." (37-year-old male patient)

\subsubsection{Cultural Factors}

$>$ Health seeking behaviour. Only one female participant had a visit to a faith healer in the initial months of her illness. With the continuous intervention by ASHA worker, she was restored to proper medical treatment (Table 3).

$>$ AYUSH (Ayurveda, Unani, Siddha and Homeopathy systems of medicine): Only two participants had approached and was inclined towards Ayurveda treatment initially and had purchased medicines from Ayurveda pharmacy (Table 3).

> Belief System and rituals Almost all the participants relied upon traditional plant-based medicines in the early days. Except two, all visited temples, performed Poojas and tied sacred threads in the initial months of TB for thwarting "evil eye" and "spirits" and approached RNTCP centre when they did not find any progress in their condition (Table 3).

"At first I didn't take herbal medicines too. I believe that the diseaselillness will be cured by itself. Usually, I do not take medicines, if I happen to take medicines at all, it would be herbal." (31-year-old male patient)

According to one health care provider about health seeking behaviour.

"The concept of sickness which we acknowledge and what the tribal people in the inner colonies acknowledge are different. Though they have some difficulty due to the illness, they try to adjust. If we are suffering from fever, we approach the doctor. But they approach the doctor at a later stage when they are so ill that they aren't even able to walk or have their food."

Stigma and discrimination because of caste and TB

Almost all the participants never perceived any discrimination from his/her family, community and from the health care provider. Patients withdrew themselves from social gatherings because they acquired the information after their hospital visit regarding the spread of disease. People from the respective neighbouring communities were also very cooperative and didn't show any indifference towards the patients. Only one female participant told about the indifference shown by neighbours (Table 3 ).

"I know TB will spread to others, but no one told me to stay away. All are my relatives only, they never said but I was careful as per doctors' advice." (16-year-old female patient)

\section{$>$ Language barrier}

Participants never felt communication problem to express their feelings and symptoms since they could talk in the Malayalam language too though all tribal groups have their own dialects (Table 3). 


\subsection{Challenges Encountered by Health Care Providers}

We conducted six key informant interviews of health care providers which included Medical Officer-Tuberculosis Control, RNTCP Consultant, Coordinator, Senior treatment supervisor, ASHA workers, and Anganwadi teacher. All of them had a varied experience of delivering TB care services ( 3 - 20 years).

\subsubsection{Enablers for Smooth Implementation}

$>$ Providers from the same population

Few of the health providers working in the region were of tribal origin and that was leverage and facilitating factor for establishing a good rapport with TB patients (Table 4).

$>$ Perception of health staff

All were very cordial and actively involved with the patients irrespective of their caste or tribes (Table 4).

\section{Intersectoral collaboration}

All participants adhered well to the treatment without missing doses only because of the collective active participation of health staffs at each level. Constant monitoring, encouragement and well-planned liaison with tribal and health department at all stages helped the treatment process and got favourable results (Table 4).

\section{$A$ health care provider with 7 years' experience narrated}

"We have started the compulsory supply of nutritious food for MDR TB patients from the tribal community with the support of the panchayat. We have coordinated with ITDP in 2014 and started the supply of nutritious food for all tribal TB patients. Earlier adherence level was very low among the tribal people when compared to non-tribal people. After the implementation of this scheme, tribal patients started adhering more to the treatment and their motivational level increased because they were getting food now. Moreover, the revenue department has started giving pension (Rs.1000/-) for TB patients, all these factors helped tribal TB patients to adhere more to the treatment."

\section{(d) Training}

All staff attended training programmes frequently that helped them improve their knowledge of TB and medication regimen and became well-aware of the importance of communication (Table 4).

\subsubsection{Perceived Barriers for Implementation}

$>$ Intense belief in spirituality

Challenging conditioned behaviour during illness since participants had a mixed belief system. Some are inclined to home remedies and others towards poojas (Table 4).

$A$ health staff with 12 years of experience remarked

"They perform some Poojas initially. Usually, these community people are like that. They perform Poojas whenever they fall ill. At a later stage only, they visit a doctor. They think that GOD will cure their disease" 
"During the first few months, we thought it was the 'evil spirit (peypidichathanu)' so we performed some Poojas."

\section{Substance abuse}

Majority of the male patients was alcoholic, so health staff had to put extra efforts to get the desired results (Table 4).

$A$ health staff with 20 years of experience said

"Alcoholism is the biggest challenge among tribal patients. When we go and meet them, they will swear that they have stopped alcoholism, but they continue, they drink most of the evenings, and we cannot help it, because we can't be there with them for 24 hours. But for me, it's great that many people had returned to life through treatment

$A$ health staff with 7 years' experience narrated

"General population has always wanted to live for tomorrow and for the children, but tribal people do not have such notions. People from other castes are worried about death and they do take medicines but tribal patients except for people from Kurichiya tribal, are less motivated to move forward in life. Yet, patient-centred approach of RNTCP helped them get quality care and that improved their condition"

\section{$>$ Animal confrontation}

ASHA workers from deeper forest areas faced animal confrontation. Even the vehicle drivers were also hesitant to come in special circumstances (Table 4).

\section{$>$ Transportation}

Long distance to remotest communities was a disturbing factor at daytime as well as in the evening especially when the patients encountered any emergency.

\section{> Disaster Prone areas}

Many tribal communities are situated in disaster-prone areas. During floods, all health staff was actively engaged and coordinated with the other departments as well as the community. So, the geographical landscape was an important factor (Table 4).

$A$ health care staff with 8 year's experience remarked

"We do face challenges to bring patients from the forest area. We can easily reach the colonies near the main road, but it is a bit harder to go to forest areas. But we never fail to provide treatment to anyone due to any of these traveling issues. No, we never stop providing medicines due to any reason. At any cost, we try our best to provide medicines. It was in 2018, during the floods, we faced some issues regarding the availability of medicines, regarding expiry dates. But somehow we managed it and never stopped providing medicines."

\section{Discussion}

It is one of the few studies that has explored the adherence to tuberculosis treatment within a context of personal, social and cultural background of the patients and reported the challenges faced by the health system to deliver health care services to a tribal population. 
The main findings of our study highlighted that the tribal TB patients were receptive and had a positive approach towards health care services. The tribal communities live in various ecological conditions ranging from plain, hills and hard to reach areas. They are at different stages of social, economic and educational development. In this scenario, we need to consider the social context while giving the treatment since adherence to TB management is closely connected with the same [10]. The study provided information on several factors that acted as enablers to adherence. They were awareness about TB, motivation, employment, treatment duration, family, community and government support, stigma and discrimination and belief systems. Similar studies were conducted and concluded that patient adherence to their medication regimens was influenced by the interaction of personal and social factors [6] [11].

Most of the patients were leading a hand to mouth existence relying on casual labor to survive. After diagnosed TB most of them left the job and adhered well with treatment only because of the support from their family and community. These findings are consistent with the study findings reported in other countries [2] [13].

Cultural factors like health-seeking behavior, language barrier, and stigma, and discrimination all were contributory to treatment adherence of patients. The study results reflected the influence of traditional beliefs that resulted in delayed seeking care and showed the importance of communication and lack of stigma in the care of TB. A large number of patients had no stigma because of caste and TB [11] [14] [15].

Health system factors played a major role in TB management. The attitude of health staff and continuous health education about the importance of medication paved ways for positive adherence. The same was reported in a study conducted in Ghana [16] [17].

The results drawn from the study proved that the health system is an important factor influencing adherence in tribal settings. Strong commitment by ASHA workers, treatment supervisors and other field staff who were in direct contact with patient, paved ways for positive treatment outcomes in this study [17] [18] [19]. Studies have reflected that reliance on personal commitment "beyond duty "rather than on program structure is one of the important enablers of treatment adherence. This study highlighted and proved the importance of personal commitment to health care staff at all levels [6].

This study has very specifically noted the role and knowledge, attitude, practice and perceived barriers of ASHA workers in TB management. The current study has highlighted the importance of intersectoral collaboration in delivering health care services with a holistic approach which was similar to other settings [19] [20].

Studies have shown that social environment interacts with biology and has repercussions on the prevention or progression of the disease to different stages [10]. The strategies developed by the public health programme should attach the cultural context for programme management. The findings on the alcoholism 
faced by health staff were similar to those found in earlier studies on TB and treatment adherence [21] [22].

The study has the following strengths and limitations. The strengths are 1) the patients were interviewed at their home or whichever place convenient for them, patients felt free to answer and it resulted in credibility of the data; 2) Health care staff were accompanied investigator while collecting data from forest areas so the bias involved is minimal; 3) We accessed a good number of patients though there were issues of accessibility and patients being alcoholics. The limitations are 1) There could be minimal errors during the transcription of the data; 2) The findings of the study should be generalized to other settings with caution as it is context specific. Based on the study findings we suggest following recommendations to the programme. 1) Active TB case finding in all the tribal villages at least once in a quarter should be carried out by the general health staff. Eventually, it helps to spread awareness among the population and help in early diagnosis and increased adherence rate; 2) The ASHA workers working in hard to reach areas probably needs to be incentivised at a higher rate when compared to the workers working in plain areas; 3 ) Addressing the substance abuse specifically alcohol should be an integral part of the programme. The skill sets to address these issues among the health care workers should be adequately capacitated.

\section{Conclusion}

The tribal TB patients are receptive and have a positive approach to health care services. Good treatment adherence can be anticipated if patient care is through a customized approach by health care providers. A holistic approach towards disease management and community development with sustainable intersectoral coordination would help in favourable treatment outcomes.

\section{Acknowledgements}

This research was conducted as a part of the "National Operational Research Training Course 2018-19" organised by Project Axshya, funded by The Global Fund and implemented by The International Union Against Tuberculosis and Lung Diseases (The Union), South-East Asia Regional Office, New Delhi, India. The training course was conducted in collaboration with Revised National Tuberculosis Control Program, Ministry of Health and Family Welfare, Government of India and National Institute for TB and Respiratory Diseases, New Delhi, India.

The training is based on "The Union/Medécins sans Frontières (MSF)" model OR course and has been acknowledged/accredited by the Special Programme for Research and Training in Tropical Diseases at the World Health Organization (WHO/TDR) under SORT IT (Structured Operational Research and Training Initiative). Mentorship and facilitation for this course was provided through The Union South-East Asia Office, New Delhi; the Centre for Operational Research, 
The Union, Paris, France; Baroda Medical College, Vadodara; Médecins Sans Frontières, New Delhi; ESIC Medical College and PGIMSR, Bengaluru; North Delhi Municipal Corporation Medical College, Hindu Rao Hospital, New Delhi; GMERS Medical College, Vadodara; Postgraduate Institute of Medical Education and Research, Chandigarh, India; Yenepoya Medical College, Mangalore. My deepest gratitude to Wayanad Social Service society, RNTCP Kerala, State tribal development department, District Tuberculosis officer Wayanad, ASHA workers, and Anganwadi teachers and all others who rendered their support throughout my study and me thank my respondents for their cooperation. My special thanks to Senior treatment supervisor Mr. Maniyan for his cooperation throughout my data collection and to Mrs. Noorjahan Kannamjeri for her guidance on data analysis.

\section{Funding}

The training course under which this research was conducted, and open access publication charges was funded by, The Global Fund to Fight AIDS, Tuberculosis, and Malaria (GFATM). The funders had no role in study design, data collection, and analysis, decision to publish, or preparation of the manuscript.

\section{Conflicts of Interest}

The authors declare no conflicts of interest regarding the publication of this paper.

\section{References}

[1] World Health Organization (2018) Global WHO Report on Tuberculosis 2018. Geneva.

[2] Rohit, R.T., Niranjan, A. and Pawan, P.A. (2018) Socio-Demographic Profile and Outcome of TB Patients Registered at DTC Rewa of Central India. Indian Journal of Tuberculosis, 65, 140-144. https://doi.org/10.1016/j.ijtb.2016.11.015

[3] Purty, A.J., Mishra, A.K., Chauhan, R.C., Prahankumar, R., Stalin, P. and Bazroy, J. (2019) Burden of Pulmonary Tuberculosis among Tribal Population: A Cross-Sectional Study in Tribal Areas of Maharashtra, India. Indian Journal of Community Medicine: Official Publication of Indian Association of Preventive \& Social Medicine, 44, 17-20. http://www.ncbi.nlm.nih.gov/pubmed/30983707

[4] Ogundele, O.A., Moodley, D., Pillay, A.W. and Seebregts, C.J. (2016) An Ontology for Factors Affecting Tuberculosis Treatment Adherence Behavior in Sub-Saharan Africa. Patient Preference and Adherence, 10, 669-681. https://doi.org/10.2147/PPA.S96241

[5] Sagbakken, M., Frich, J.C. and Bjune, G.A. (2008) Perception and Management of Tuberculosis Symptoms in Addis Ababa, Ethiopia. Qualitative Health Research, 18, 1356-1366. https://doi.org/10.1186/1471-2458-8-11

[6] Gebreweld, F.H., Kifle, M.M., Gebremicheal, F.E., Simel, L.L., Gezae, M.M., Ghebreyesus, S.S., et al. (2018) Factors Influencing Adherence to Tuberculosis Treatment in Asmara, Eritrea: A Qualitative Study. Journal of Health, Population, and Nutrition, 37, 1. https://doi.org/10.1186/s41043-017-0132-y 
[7] Jana, A. and Basu, R. (2017) Examining the Changing Health Care Seeking Behavior in the Era of Health Sector Reforms in India: Evidences from the National Sample Surveys 2004 \& 2014. Global Health Research and Policy, 2, 6. https://doi.org/10.1186/s41256-017-0026-y

[8] Chandran, D. (2012) A Paradox within a Paradox: Emerging Signs of Change in the Unappealing Tribal Scenario in Kerala, India. Developing Country Studies, 2, 1-11. http://www.iiste.org/Journals/index.php/DCS/article/view/2190

[9] Open Government Data Platform India (1991) Religion Wise Population, Census, India and States. https://data.gov.in/catalog/religion-wise-population-census-1991-india-and-states

[10] Wurie, F.B., Cooper, V., Horne, R. and Hayward, A.C. (2018) Determinants of Non-Adherence to Treatment for Tuberculosis in High-Income and Middle-Income Settings: A Systematic Review Protocol. BMJ Open, 8, e019287. https://doi.org/10.1136/bmjopen-2017-019287

[11] Diefenbach-Elstob, T., Plummer, D., Dowi, R., Wamagi, S., Gula, B., Siwaeya, K., et al. (2017) The Social Determinants of Tuberculosis Treatment Adherence in a Remote Region of Papua New Guinea. BMC Public Health, 17, 70. https://doi.org/10.1186/s12889-016-3935-7

[12] Census (2011) Wayanad District Population Census 2011-2019, Kerala Literacy Sex Ratio and Density [Internet]. https://www.census2011.co.in/census/district/273-wayanad.html

[13] Bhattacharya, T., Ray, S., Biswas, P. and Das, D. (2018) Barriers to Treatment Adherence of Tuberculosis Patients: A Qualitative Study in West Bengal, India. International Journal of Medical Science and Public Health, 7, 396. https://doi.org/10.5455/ijmsph.2018.0102220022018

[14] Marston, B.J., et al. (2011) Care Seeking and Attitudes towards Treatment Compliance by Newly Enrolled Tuberculosis Patients in the District Treatment Programme in Rural Western Kenya: A Qualitative Study. BMC Public Health, 11, Article No. 515.

[15] Munro, S.A., Lewin, S.A., Smith, H.J., Engel, M.E., Fretheim, A. and Volmink, J. (2007) Patient Adherence to Tuberculosis Treatment: A Systematic Review of Qualitative Research. PLoS Medicine, 4, 1230-1245. https://doi.org/10.1371/journal.pmed.0040238

[16] Annan, A., Singh, A., Dogbe, J., Asante, D. and Owusu-Dabo, E. (2014) Health-Seeking Behaviour of Tuberculosis Patients and Related Factors in the Central Region of Ghana. Journal of Science and Technology, 33, 27-38. https://doi.org/10.4314/just.v33i3.4

[17] Sagare, S.M., Bogam, R.R., Murarkarsujata, S.K., Patil, U.P. and Ghate, M.M. (2012) Knowledge, Attitude and Practices of ASHAs Regarding Tuberculosis and DOTS. Indian Journal of Science and Technology, 5, 2401-2404.

[18] Sahile, Z., Yared, A. and Kaba, M. (2018) Patients' Experiences and Perceptions on Associates of TB Treatment Adherence: A Qualitative Study on DOTS Service in Public Health Centers in Addis Ababa, Ethiopia. BMC Public Health, 18, Article No. 462. https://doi.org/10.1186/s12889-018-5404-y

[19] van der Werf, M.J., Kotila, S. and Hollo, V. (2014) Healthcare System Factors Influencing Treatment Results of Patients with Multidrug-Resistant Tuberculosis. ECDC Technical Report.

[20] De Vries, G., Tsolova, S., Anderson, L.F., Gebhard, A.C., Heldal, E., Hollo, V., et al. (2017) Health System Factors Influencing Management of Multidrug-Resistant Tu- 
berculosis in Four European Union Countries-Learning from Country Experiences. BMC Public Health, 17, 334. https://doi.org/10.1186/s12889-017-4216-9

[21] Bagchi, S., Ambe, G. and Sathiakumar, N. (2010) Determinants of Poor Adherence to Anti-Tuberculosis Treatment in Mumbai, India. International Journal of Preventive Medicine, 1, 223-232.

[22] Ghatage, S., Aithal, S. and Angadi, N. (2018) A Study on Reasons for Nonadherence to 99DOTS among HIV-Tuberculosis Coinfected Patients in Davanagere District, Karnataka. International Journal of Medical Science and Public Health, 7, 805-808. https://doi.org/10.5455/ijmsph.2018.0618015062018 